\title{
Variations
}

Variations Revue internationale de théorie critique

12 | 2008

Wärmestrom

\section{Nous sommes dans une époque de restauration}

\section{Pierre Bourdieu}

\section{OpenEdition}

\section{Journals}

Édition électronique

URL : http://journals.openedition.org/variations/248

DOI : 10.4000/variations.248

ISSN : 1968-3960

\section{Éditeur}

Les amis de Variations

\section{Édition imprimée}

Date de publication : 21 décembre 2008

Référence électronique

Pierre Bourdieu, « Nous sommes dans une époque de restauration», Variations [En ligne], 12 | 2008,

mis en ligne le 01 janvier 2012, consulté le 05 mai 2019. URL : http://journals.openedition.org/

variations/248 ; DOI : 10.4000/variations. 248

Ce document a été généré automatiquement le 5 mai 2019.

Les ami•e•s de Variations 


\title{
Nous sommes dans une époque de restauration
}

\author{
Pierre Bourdieu
}

\section{NOTE DE L'ÉDITEUR}

Première publication sur www.theoriecritique.com, « Wärmestrom, le courant chaud en sciences humaines ", Hiver2008/2009, pp. 97-98

La publication du présent texte a été accordé à Alexander Neumann par Pierre Bourdieu en 1998, à l'occasion de sa première parution en français dans les colonnes d'un supplément aux Inrockuptibles (« Nous qui n'étions pas nés en 68 »), assorti de la mention « Nous remercions Pierre Bourdieu de nous avoir autorisé à publier ce texte inédit en français ». Nous le reproduisons de façon inchangée avec l'accord de la responsable de la publication dont il est question, Christel Pesme (Los Angeles). Voir aussi Alexander Neumann (dir.), Les perspectives de la protestation (actes du colloque européen du même nom organisé autour d'une intervention de Pierre Bourdieu à Francfort-sur-le-Main en 1996), Syllepse, Paris, 1998.

1 Nous devons développer de nouvelles formes de combat pour contrecarrer par des moyens appropriés la violence de l'oppression symbolique qui s'est peu à peu installé dans les démocraties occidentales.

2 Je pense à la censure larvée qui frappe de plus en plus la presse critique et, dans les grands journaux officiels, la pensée critique. Nous en avons fait l'expérience très directement quand nous avons eu à nous opposer à la guerre du Golfe. La presse soidisant progressiste, qui s'était elle-même prise d'enthousiasme pour la guerre, refusait nos textes ou veillait à les assortir de textes favorables à la guerre. Plusieurs journaux anglais ont refusé de publier le très beau poème écrit par Harold Pinter pour dénoncer la guerre (nous l'avons fait paraître plus tard dans Liber). La vie politique, comme la vie intellectuelle, sont de plus en plus soumises à la pression des médias - à commencer par 
la télévision - qui sont eux-mêmes soumis à la pression des annonceurs ou tout simplement à une obligation de bonne conduite qui exclut toute possibilité de critique.

3 L'Internationale conservatrice, qui a pour centre les Etats-Unis, fait pression sur tous les espaces d'expression libre, comme les musées, et réprime les recherches d'avant-garde en contrôlant l'octroi des subventions publiques, sous prétexte de pornographie ou d'atteinte à l'ordre public.

Nous sommes dans une époque de restauration.

5 Des critiques médiocres et des écrivains insignifiants dénoncent l'art moderne comme une pure tromperie, et en appellent à une réconciliation du roman avec les formes narratives traditionnelles. Sans parler des sciences sociales, sur lesquelles pèse constamment le soupçon. Le débat sur la Révolution française (que le livre de Kaplan a bien analysé) a remis à la mode les vielles idéologies anti-révolutionnaires. Les courants individualistes et ultra-subjectivistes qui dominent l'économie et qui sont en passe de conquérir l'ensemble du champ des sciences sociales (avec Gary Becker, en particulier), tendent à saper les fondements même de la science sociale.

6 C'est dans la sphère intellectuelle que les intellectuels doivent mener le combat, non seulement parce que c'est sur ce terrain que leurs armes sont les plus efficaces, mais aussi parce que c'est le plus souvent au nom d'une autorité intellectuelle que les nouvelles technocraties parviennent à s'imposer. La nouvelle démagogie s'appuie principalement sur les sondages pour légitimer les mesures répressives prises à l'encontre des étrangers, ou les politiques culturelles hostiles à l'avant-garde.

7 Voilà pourquoi les intellectuels doivent disposer de moyens d'expression autonomes, qui ne dépendent pas de sollicitations publiques ou privées, et s'organiser collectivement, pour mettre leurs armes propres au service des combats progressistes.

\section{AUTEUR}

\section{PIERRE BOURDIEU}

Sociologue (1930-2002), professeur au Collège de France 